\title{
EVIDENTIALITY AND MORALITY IN A KOREAN HERITAGE LANGUAGE SCHOOL ${ }^{1}$
}

\author{
Adrienne Lo
}

\begin{abstract}
Previous work on Korean grammar has claimed that one person can not have access to another person's thoughts, feelings or sensations, as indicated by the use of evidential markers. By looking at cases in which a teacher at a Korean heritage language school claims to read her students' minds with a high degree of certainty, I demonstrate how expressions of epistemic stance relate to moral evaluation. Speakers portray their access to the thoughts and sensations of individuals who they deem morally worthy as more distant and uncertain. When individuals are evaluated as morally suspect, however, speakers represent these persons' emotions, thoughts and sensations as self-evident displays of affect. This paper thus argues that evidential marking in Korean interaction is a social act through which interlocutors morally evaluate others.
\end{abstract}

Keywords: Evidentiality, Subjectivity, Epistemic stance, Korean language, Morality

\section{Introduction}

Research on Korean interaction has tended to concentrate on certain kinds of socially valued practices and relationships. While there is a longstanding history of research on honorifics, politeness, and indirectness (e.g. Dredge 1983; Park 1990; Sohn 1986a), ways in which Korean speakers are impolite, direct, and authoritarian have received comparatively little attention. However, what is polite and indirect has value in the Saussurean sense as such only in the ways in which it functions in a cultural system where impoliteness is equally important. In order to understand how social norms operate, we must also attend to cases in which their violation is socially meaningful (Garfinkel 1967).

Using the concept of relationality, I examine some cases in which a teacher in a Korean heritage language classroom uses culturally dispreferred ways of speaking about

1 Earlier versions of this paper were presented at the 2003 American Anthropological Association conference, the Language, Interaction, and Social Organization (LISO) group at UC Santa Barbara and the Department of Anthropology at the University of Illinois Urbana-Champaign. I thank the participants at those sessions for their helpful feedback on this work and Junghee Park and Mee-Jeong Park for their generous assistance with the Korean grammar. I am also grateful to Elaine Chun, Angela Reyes, and Steven Talmy for their detailed comments on an earlier version of this paper. All remaining errors are mine. This research was supported by grants from the UCLA Asian American Studies Center, the Spencer Foundation, and the University of California Linguistic Minority Research Institute (UC LMRI) under the UC LMRI Grants Program. Opinions reflect those of the author and do not necessarily reflect those of the grant agencies. 
her Korean American students. Specifically, I examine a series of narratives in which she uses different frameworks of subjectivity to talk about students she is assessing as moral subjects. When she is assessing students as morally exemplary, the teacher uses culturally preferred frameworks in which she situates her knowledge of their feelings, sensations, and emotions as relatively distant through evidential marking. When she is assessing students as morally lacking, she uses culturally dispreferred frameworks with no evidential marking which situate her knowledge of their feeling, sensations, and emotions as more certain. By looking at how the evidential patterning of these narratives intersects with moral evaluation, I argue that evidential marking is not a reflection of a speaker's cognitive stance towards others, but a resource for indexically constructing others as different kinds of moral beings.

I discuss how this interactional approach can help shed light on two seemingly contradictory claims in the social science literature about Korean speakers. Whereas research by Korean linguists has claimed that Korean speakers cannot have access to other people's thoughts and internal sensations, research by psychologists and anthropologists has argued that Korean speakers are in fact always trying to divine the "true" thoughts and feelings of others, using the principle of nwunchi. By looking at these claims as articulations of social norms of a specific type of Korean interaction, I illustrate how the teacher's narratives can also be read as attempts to socialize Korean American children to a theory of interaction and affective display appropriate for a heritage language classroom setting.

\section{Subjectivity}

The concept of subjectivity has been of increasing interest to linguists and linguistic anthropologists lately. Most linguists date this concept to Benveniste (1971), who described subjectivity in terms of the ability of speakers to view themselves as subjects. "Language is marked so deeply by the expression of subjectivity that one might ask if it could still function and be called language if it were constructed otherwise," he wrote (1971: 225). While Benveniste discussed deictics and tense, he highlighted the role of personal pronouns. By contrasting minimal pairs of sentences with either first person or third person subjects, he argued that sentences with the subject "I" draw attention to the speaker's attitude while sentences with the subject "he" or "she" are more descriptive. Benveniste's work thus highlighted the deictic character of subjectivity as a relationship between speakers and their utterances.

One continuing theme in the subjectivity literature involves the contrast between "subjective" and "objective" utterances. Lyons (1982: 107), for example, contrasts the following two sentences:

I remember switching off the light

I remember myself switching off the light

In his interpretation, the second sentence foregrounds the "objective observing self" because the speaker is taking a distanced perspective on herself, while the first foregrounds a "subjective experiencing self" because it is more anchored in the speaker's own consciousness. According to Lyons, the distinction between these two perspectives is gradual, and can be thought of as a continuum between the "objective" 
component of language, which communicates propositions, and the "subjective" component, which points to the speaker's expression of her own thoughts and beliefs.

Langacker (1985: 121) presents the following diagram to schematize these two viewpoints:

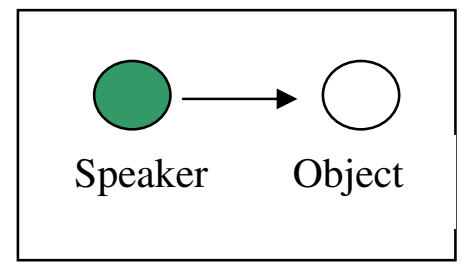

"Egocentric Viewing Arrangement"

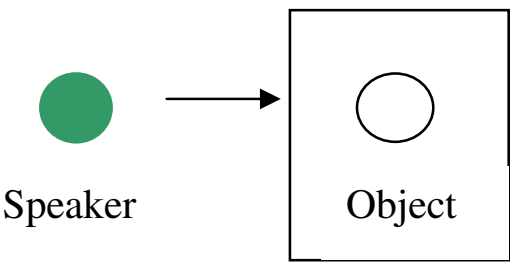

“Optimal Viewing Arrangement “

Figure 1. "Egocentric" vs. "Optimal" viewing arrangements (Langacker 1985: 121)

In the first ("egocentric viewing arrangement"), the speaker locates herself within the field of observation, as an observer of a particular object, while in the second ("optimal viewing arrangement") she does not. Describing the second situation, Langacker (1985: 121) writes, "S focuses his attention solely on $\mathrm{O}$, to the point that conscious awareness of SELF either fades away entirely or is greatly diminished. What $S$ observes, in other words, is $\mathbf{O}$, not $\mathbf{S}$ observing $\mathbf{O}$ " (emphasis in the original). Other scholars have used different names for these two contrasting frameworks. Iwasaki (1993) uses the terms Sperspective vs. O-perspective in his discussion of subjectivity in Japanese, for example, while Maynard (1993: 51) contrasts the narrative internal position, where "one locates oneself internal to the scene" with the narrative external position, where "the language producer describes the event as an outside observer." A wide range of grammatical features have been analyzed as relating to subjectivity, including tense, subject marking, personal pronouns, switch-reference, adverbs, verbal structures, quotatives, sentencefinal particles, etc. (see Iwasaki 1993; Maynard 1993; and Scheibman 2002 for surveys of work on subjectivity in English and Japanese).

\subsection{Evidentiality and subjectivity}

While earlier work on subjectivity concentrated on personal pronouns and tense, recently scholars have begun to look at the relationship between subjectivity and evidential forms which mark epistemic stance. Maynard (1993: 122) for example, argues that modal adverbs such as "as expected", "probably", and "certainly" "do not directly modify verbs, but rather, express the speaking self's subjective, often emotional feelings and attitude toward and evaluation of what is to be stated." Recent work by Mushin (2001) argues that subjectivity is not in fact a dichotomous relationship, but rather a continuum between poles of "subjective" and "objective" frameworks. In her analysis, speakers' expressions of epistemological stance (which include, but are not limited to the linguistic forms which come under the traditional label of 'evidentiality') deictically project different degrees of subjectivity: 
Subjective

Conceptualiser is

Evoked
Perceptual Experience

Private Experience

Objective

Conceptualiser is

Effaced

Factual

Figure 2. Relationship of epistemological stance to subjectivity (Mushin 2001: 81)

While Mushin's taxonomy situates frameworks of epistemic stance as reflecting fundamentally cognitive, cross-linguistic "conceptual structures" rather than social positioning, her delineation of the links between the use or absence of evidentials and projections of subjectivity highlights the relationship between these two linguistic phenomena.

\section{Epistemic stance}

In order to understand exactly how the presence or absence of evidential marking helps to construct different kinds of subjectivity, it is useful to consider the ways in which evidentiality is fundamentally deictic. Asif Agha (2004) notes that what has been studied under the rubrics of subjectivity and evidentiality is perhaps better conceptualized as the intersection of two different phenomena: 1) participant-centering and 2) epistemic evaluation. These come together to create epistemic stance. In his model, epistemic evaluations include both forms which mark the degree of certainty (e.g. conviction, doubt, or commitment) as well as those that function as evidentiary warrants (e.g. the source of knowledge).

These evaluations are then mapped onto configurations of participants through the mechanism of participant-centering. Whereas most accounts of subjectivity look only at how the speaker positions herself in relation to the information she is imparting, the phenomenon of participant-centering recognizes that the deictic origo may be centered not only in the speaker (as in the "subjective" perspective), but also in the addressee or in persons external to the immediate configuration of speaking (as in the "objective" perspective), and in complex combinations of these participants. Agha's model enables us to understand how the expression of epistemic stances in interaction creatively indexes (Silverstein 1976) a participation framework through the mechanism of participant-centering.

\section{Speaking about others' thoughts, feelings, and sensations}

In this paper, I will be looking at a claim which has been made in both the subjectivity literature as well as the literature on evidentiality. It is often argued that speakers in certain cultures are not able to "directly" represent the thoughts, feelings, and sensations of other people. This has been claimed for languages from a number of different 
language families, including Japanese (Kuroda 1973; Kamio 1995), Korean (Kim 1978; Lee 1993), and various indigenous languages spoken in both North and South America (e.g. Aikhenvald 2003: 149; McLendon 2003: 103-4; Reuse 2003: 93). Speakers are said to be able to use certain kinds of verb forms and evidential markers when speaking of their own thoughts, feelings, and sensations, but must use different ones when speaking about other parties. ${ }^{2}$ These kinds of grammaticality judgments, which are often based on intuition or elicitation and not on actual language use, are often interpreted as reflecting speakers' lack of cognitive access to others' thoughts and beliefs.

By looking at how evidential marking works in interaction, I will demonstrate that evidential marking is not in fact a reflection of cognitive access, but a kind of social action. I examine how expressions of epistemic stance construct others' subjectivities as more or less accessible and how speakers use grammar in interaction as a resource for indexically constituting others as different kinds of moral beings.

\section{Towards a Korean theory of mind: The grammatical perspective}

Linguists working on evidentiality have claimed that Korean speakers must mark statements about the thoughts, feelings, and sensations of other people to indicate their indirect access to other people's minds. This line of research claims that "objective" or "direct" statements about what another person is thinking, feeling, or intending are in fact ungrammatical in Korean. Hyo Sang Lee (1993), for example, claims that "the informal ending $-\hat{o}^{3}$ cannot be used to express other people's internal feelings or sensations, because the speaker does not have the authority over this kind of information. The informal ending - $\hat{o}$ also cannot be used to describe the addressee's volitional activities...because it is the addressee who has the authority over the information conveyed, rather than the speaker" (1993: 142). In the following examples, statements about internal feelings, sensations, and activities with second or third person subjects which do not have evidential marking are classified as ungrammatical because the attribution of feeling or sensation is deictically centered outside of the speaker. One way to make these "objective" sentences grammatical, according to Lee, is to mark them with the sentence-ender -kwuna. This sentence-ender, which Lee characterizes as a marker of newly perceived unassimilated information, deictically recenters the proposition, turning it into a "subjective" noticing of new information which is anchored in the speaker's observation of the other person's apparent state:

(1) 'You are cold'

* ne nun chwu-e ne chwup kwuna

${ }^{2}$ One exception to this generalization is provided by Kamio (1995: 255), who notes that speakers may use "direct" forms as performatives if they are hypnotists.

3 This -ô would be -e in Yale transcription.

${ }^{4}$ Native Korean speakers note that these sentences would be appropriate in cases where an interlocutor was contradicting an earlier assertion. For example, if someone were to deny being cold while visibly shivering, it would be acceptable to use the informal ending emphatically e.g. "You are cold!" Similarly, if a child denied going to school yesterday when in fact they did, an adult could say to 
you TOP cold-INT

'You are cold'

* cay nun sulph-e

that child TOP sad-INT

'That child is sad' you cold -UNASSIM

'[I see] you are cold!'

ne sulphe kwuna

you sad -UNASSIM

'[I see] you are sad!'

* ne nun ecay hakkyo-ey wa-ss-e

you TOP yesterday school-LOC come-PST-INT

'You came to school yesterday'

ne ecay hakkyo wa-ss-kwuna

you yesterday school come-PST-UNASSIM

'[I see] you came to school yesterday!'

(Lee1993: 141-2, 148)

Similarly, in an article about the indirect quotative marker -tay, Sung Ock Sohn and Mee Jeong Park (2003: 109) argue that -tay is used "when the speaker cannot read another's consciousness from his or her point of view." In the following interaction, taken from a bible study meeting, two women, H. and S., are talking about a pastor who is ill. Another woman, L, who is an overhearer to this conversation, asks if the pastor is sick using the indirect quotative marker -tay:

(2) 'Is someone sick?'

H.: $\quad$ But why doesn't the church pray for (her)?

S.: What prayer?

H.: $\quad$ Well, if the pastor is sick people should pray for her once in a while

L.: $\quad$ nwuka aphu-tay-yo?

someone sick-QT-POL

'Is someone sick-TAY?'/'Did somebody say someone is sick?'

H.: $\quad$ Oh, pastor Y. She had surgery and

L.: $\quad$ Oh, I didn't know that.

(Sohn and Park 2003: 109) ${ }^{5}$

them "You did come to school yesterday" using the informal ending. (E. Chun and J. Park, personal communication)

${ }^{5}$ In lee's original article, these examples were transcribed according to a mixed system of Yale and McCune-Reischauer romantization. I have transcribed and coded all of the excerpts in this article according to the system used to transcribe the conversational examples below, for the sake of consistency. Transcription conventions:

ACC: accusative case marker, ADV: adverbial, CIRCUM: circumstantial, COMM: committal, CONN: connective, DAT: dative case marker, DC: declarative mood, DR: directional particle, FUT: future, GRND: gerundive, HT: honorific title, IN: indicative, INT: intimate speech level, LOC: locative, NOM: nominative case marker, NOML: nominalizer, PAS: passive, PLN: plain speech level, POL: polite speech 
In their discussion of this excerpt, Sohn and Park use Kamio's (1997) model of the territory of information to analyze L.'s use of the quotative:

Note further that $\mathrm{L}$ uses the short form [of the indirect quotative] instead of direct speech (i.e. the non-quotative form, apha-yo) to mark the inaccessibility of the information to the speaker. In other words, neither L. (speaker) nor S. (hearer) has access to the internal state of the person who is ill. Thus L. uses the hearsay -tay to frame the inaccessible territory of information. (2003: 109)

A similar marking of "inaccessibility" using the indirect quotative in Japanese has been described by Suzuki (1998) as a kind of "psychological distancing" of the speaker from the information presented. Here, the quotative form (aphutayyo) is deictically anchored to the speaker, whereas the direct form (aphayo), which projects "accessibility," is not. The use of the quotative thus frames the question about the pastor's illness as an "subjective" noticing, rather than a "objective" statement of fact. In her analysis of the acquisition of -tay by Korean speaking infants, Soonja Choi (1991: 112) also argues that "-TAY is also used when stating an emotional or physical state of a third person to which the speaker cannot get direct access." 6

level, PRSM: presumptive, PRS: present, PST: past tense/perfect aspect, Q: question, QT: quotative, RL: relativizer, TOP: topic marker, UNASSIM: newly perceived information marker, VOC: vocative.

$\begin{array}{ll}(.4) & \text { Pauses are given in tenths of a second. } \\ \underline{\text { Mak }} & \text { Underlining indicates emphasis. } \\ 9: 45 & \text { Italics indicates speech in English. } \\ ((\text { panting)) } & \text { Double parentheses enclose comments on the interaction. } \\ = & \text { Equal sign indicates latching. } \\ (\quad) & \text { Empty parentheses indicate speech which was unclear. } \\ , & \text { Commas indicate continuing intonation. } \\ . & \text { Periods indicate falling intonation. } \\ ? & \text { Question marks indicate rising intonation. }\end{array}$

${ }^{6}$ In the following interaction from Choi (1991), a two-year-old child uses the indirect quotative marker -tay to talk to her grandmother about a doll who is sick:

(3) 'The baby is sick'

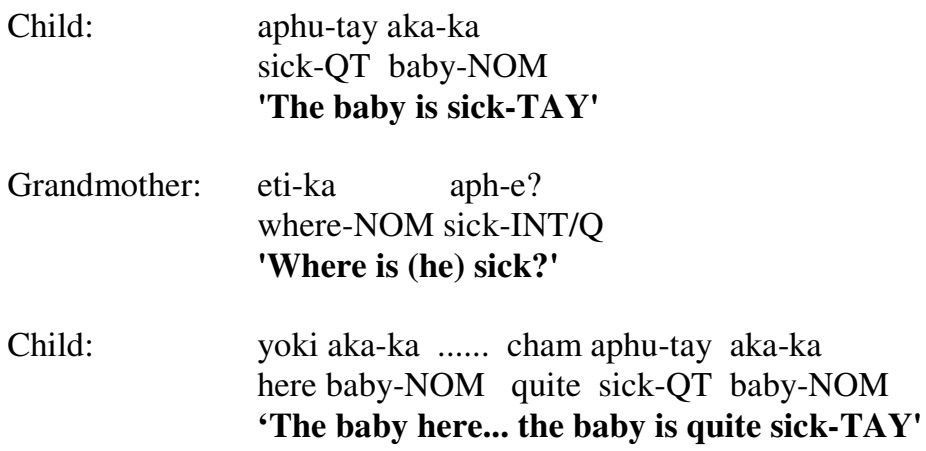

(Choi 1991: 112)

Choi (1991: 113) writes: "The suffix -TAY ...indicates that the information does not come directly from the child's experience but indirectly from another source." According to her analysis, the importance of 
Lastly, linguists working on Korean attributions of emotion have claimed that Koreans cannot make direct observations about a third party's emotions. In an article on Koreans' beliefs about emotion, Ki-Hong Kim (1978) writes:

Emotion is said to be subjective; one can feel emotion only through one's own experience... It is interesting to observe that in Korean it is ungrammatical to use emotion word [sic] with the second and third persons in the present tense. Emotion words used with the present tense are usually for the first person only. For instance, $k u$ salam un kippu-ta 'he is happy' is ungrammatical in Korean in normal context. The reason seems to be that emotions are subjective, therefore to express others' emotions seems unwarranted. However the sentence: $c e$ salam un kippe han-ta 'that man is acting (looks) happy' is grammatical although the subject is in the third person because kippe han-ta means 'acts/looks happy'. The sentence then is a simple observation by the speaker, rather than a categorical statement about the subject's emotion. (1978: 259)

According to these scholars, then, Korean grammar seems to encode the fact that speakers can not actually read another person's mind. Korean verbs which relate to someone's emotional or physical state or personal experience, they argue, can only be used in the plain form in the first person. Claims about someone else's consciousness, thoughts, feelings, and sensations, these scholars claim, must be grammatically marked with periphrastic verb constructions or verbal suffixes which indicate the speaker's indirect observation of the third party's apparent state. In Langacker's terms, this would seem to indicate that when Koreans speak about the thoughts, feelings, or emotions of other people, they must use "subjective" frameworks where the observer locates herself within the scene.

\section{Setting}

In this paper, I will discuss some apparent exceptions to these observations. I argue that the "objective" framework is not, in fact, ungrammatical in Korean, but is culturally dispreferred. It is used to describe those who are evaluated in the moment as morally inappropriate. I will be presenting excerpts from interactions at a Korean language school in California. This school, located in an ethnically mixed suburb known for the strength of its public schools, serves over 600 Korean American students every Saturday morning throughout the school year. Children attend $2 \frac{1 / 2}{2}$ hours of Korean language class and 1/2 hour of enrichment classes in soccer, basketball, music, art, Korean drumming, taekwondo, or Korean dance.

Most of the students at the school are $2^{\text {nd }}$ generation Korean Americans who may speak Korean at home but have little background in reading and writing. The excerpts I will present are taken from a middle level class of elementary school students ranging in age from 8-12. Their teacher is a Korean American woman in her late 30's who immigrated to the United States three years before this class was recorded.

\section{Reconstructing actions and feelings}

distinguishing the source of one's information in Korean is underscored by the fact that infants mark these kinds of distinctions in epistemic meaning before they use deontic modal forms. 
The first excerpt is taken from a class where the children have been misbehaving. Tardiness is a chronic issue in this class and this narrative contrasts two ways of walking into class late:

(4) 'Some very nice behavior'

1 Teacher: Kuliko Jinsok-i-lang Byungsok-i-nun onul nemwu And Jinsok-VOC-with Byungsok-VOC-TOP today too much Nemwu yeyppu-n mosup-ul sensayng-nim-hanthey Too pretty-RL appearance-ACC teacher-HT-DAT po-ye-cwe-ss-e. see/PAS give-PST-INT And today Jinsok and Byungsok showed the teacher some very very nice behavior

mwe-nya-ha-mye-nun (.4) ahop-si samsipsam-pwun what-Q/PLN-do-if-RL nine-hour thirty three-minutes i-pwun ccum-ey two-minutes around-at

Because (.4) at around 9:33 or 9:32

wa-ss-nuntey (.4) hekhekhekhek ilehkey ha-ko Come-PST-CIRCUM huhhuhhuhuh like that do-CONN wa-ss-e. come-PST-INT they came, (.4) (going) "huh huh huh huh" ((panting)), like that they came

Way kulay-ss-ul-kka. Why be so-PST-FUT/RL-Q/PRSM Why were they like that?

Way kulay-ss-ul-kka? Why be so-PST-FUT/RL-Q/PRSM Why were they like that?

$8 \quad$ Students: $\quad(\quad)$

9 Teacher: e. (.2) cokum-ilato ppalli o-l-lyeko, yes a little-even fast come-FUT/RL-in order to Yes (.2) even though (they were only) a little (late), they came quickly. 
10 sensayng-nim-hantey mianha-n maum chinkwu-tul-hantey Teacher-HT-DAT be sorry-RL feeling friends-PL-DAT

mianha-n maum-i iss-ese ttwie-o-n be sorry-RL feeling-NOM be-CONN run-come-PST/RL

kes kath-ass-e. thing seem-PST/INT

They must have been running because they felt sorry towards the teacher and sorry towards their friends.

tulewa-ss-nuntey hekhekhekhek come in-PST-CIRCUM ((panting sounds)) When they arrived, (they were going) "huh huh huh huh" ((panting))

Ama pwunmyenghi kulay-ss-ul-ke-ya. probably certainly be so-PST-FUT/RL-fact-be-INT Probably, certainly, they must have been like this:

Emma na hakkyo nucu-myen an-tway-yo.

Mom I school be late-if not-become-POL

"Mom, I can't be late for school"

Halmeni na ppalli ka-ya-tway-yo.

Grandmother I quickly go-must-become-POL

"Grandma, I really have to go."

kuntey yeki o-ta ((points)) po-nikka cokum nuc-ess-e.

But here come-while see-because a little late-PST-INT.

Then when they came ((points)) they realized they were a little late,

Mak ttwi-ess-ul-ke-ya. fully run-PST-FUT/RL-thing-be-INT

so they must have really run hard.

((Teacher closes eyes and pretends to "run"))

Kuntey etten chinkwu-nun nuc-key tulewa-ss-nuntey,

But some friend-TOP late-ADV come in-PST-CIRCUM

But although some friends came in late,

((Teacher imitates uncaring walk of other students)) 
19

Chinkwu-tul-hantey mianha-n maum-to eps-e. Friend-PL-DAT be sorry-RL feeling-even not be-INT They don't even feel sorry towards their friends

Sensayng-nim mianhay-yo ha-nun chinkwu-to eps-e. Teacher-HT be sorry-POL say-PRS/RL friend-even not be-INT None of these friends even say "Teacher, I'm sorry"

Chenchenhi wa-ss-nuntey, (.2) koaynchanh-ci mwe. Slowly come-PST-CIRCUM be alright-COMM what They came in slowly, (.2) "Well, it's ok, whatever."

Ku-ke-nun koaynchanh-un ke-l-kka

That thing-TOP be alright-RL thing-FUT/RL-Q/PRSM Is that something which is ok?

=koaynchanh-ci anh-un-ke-l-kka. be alright-NOM not be-PRS/RL-thing- FUT/RL -Q/PRSM $=$ Is that something which is not ok?

((Teacher walks behind desk $))$

Ette-n ke-l-kka-yo?

Which-RL thing-PRS-PRSM-POL Which one is it?

In this narrative, the teacher uses different kinds of evidential marking to talk about students she is praising vs. those she is criticizing. When talking about the "good" Jinsok and Byungsok, she positions her utterances as deductions and suppositions. When talking about the "bad" students, she describes their actions, thoughts, and emotions with no evidential marking. The teacher here thus uses different frameworks of subjectivity for the "bad" students and the "good" students. She positions her epistemic stance towards the "good" students as relatively uncertain, deictically locating her own presence as an observer of them, and employing a culturally preferred "subjective" participation framework. In contrast, she constructs her epistemic stance towards the "bad" students as relatively certain. By not using evidential marking to talk about the "bad" students and deictically centering her observations of their behavior as emanating from the students themselves, the teacher employs a culturally dispreferred "objective" participation framework The contrast between these two frameworks shows how grammar helps to construct others as opposing types of moral beings.

In lines 10 through 11, for example, the teacher states "They must have been running because they felt sorry towards the teacher and sorry towards their friends." This statement, which describes the behavior of Jinsok and Byungsok, is discursively marked as uncertain through the 'ttwieon kes kathasse" construction, e.g. 'it seemed that they ran', Here, Jinsok and Byungsok's behavior is embedded within a grammaticalized form for indicating uncertainty consisting of a relativized past noun clause with the verb katha 'to seem, to be like.' In lines 16-17, the deductive nature of the teacher's 
expression "Then when they came they realized they were a little late, so they must have run really hard" is made evident through the "ess-ul-ke-ya" verb ending, where the embedding of the verb 'to run' within a past noun clause with the future relativizing infix $-u l$ indicates presumption (Suh 1996). In both of these cases, statements about Jinsok and Byungsok's behavior and emotions are embedded within frameworks in which it is made evident that these represent the teacher's conjectures about their activities.

When the teacher talks about how the second group enters the classroom, however, her statement in line 21 does not have any evidential marking: "They came in slowly, and 'Well, it's OK, whatever.' " In contrast to the first framework which highlighted the teacher's perspective, this framework locates the origo of the actions and projected affect within the students themselves. In using the plain, unmarked form of the verb to talk about the entrance of the second group of students, but evidentially marked forms to talk about the entrance of Jinsok and Byungsok, the teacher positions herself as relatively more uncertain and distant from the students she is praising, but relatively more certain towards the students whose behavior she is criticizing.

This contrast can also be seen in the teacher's use of direct quotation. In the case of Jinsok and Byungsok, the quotes are set off with an explicit introductory frame that indicates that they are conjectures: "Probably, certainly, they must have been like this" (line 13), which reprises the -ul ke presumptive ending discussed above. In the case of the other students, the framing of the quote does not point to the teacher: "They came in slowly, 'Well, it's OK, whatever'" (line 21). Whereas the evidential marking and framing of line 13 clearly distinguishes the teacher's voice as animator from the speech she conjectures Jinsok and Byungsok to have spoken as authors earlier that morning, in line 21 there is no such distinction. The teacher's statement in line 21 thus erases her own role as author of the lines she imputes to the students, locating this disdainful stance as emanating directly from the students themselves, rather than in the teacher's interpretation of their demeanor.

This same contrast in framework can also be seen in the ways in which the teacher characterizes their emotional states. Recall the earlier claims that Koreans cannot speak directly of a third party's emotional state because "express[ing] others' emotions seems unwarranted" (Kim 1978: 259). In this case, however, the negatively assessed students' emotional state is embedded within a matrix clause which uses a bare form of the verb ("They don't even feel sorry towards their friends." [line 19]) while the teacher's characterization of the positively assessed students' emotional state is framed by a clause which is deductively marked by the - $u l$ ke ending: "They must have been running because they felt sorry towards the teacher and sorry towards their friends (line 11)": While the same phrase, mianhan maum. or the feeling of being sorry is used for both the positively and the negatively evaluated students in lines 10,11, and 19, the discursive embedding of this clause nevertheless reveals contrasting epistemic stances.

This contrast in evidential patterning is paralleled by other ways in which the teacher's narrative discursively constructs Jinsok and Byungsok as agents who are morally responsible for their actions. The fact that they are given names, for example, while the bad students are only referred to with the indefinite "some students" makes Jinsok and Byungsok's actions more salient and spotlights their behavior as behavior to be emulated. Moreover, her depiction of Jinsok and Byungsok uses verb forms which emphasize their agency. In the abstract of the narrative, for example, Jinsok and Byungsok's behavior is characterized with a benefactive form which discursively 
constructs their running as an action which was intentionally projected towards the teacher. ("And today Jinsok and Byungsok showed the teacher some very very nice behavior" [lines 1-3]) In line 9 ("Yes (.2) even though (they were only) a little (late), they came quickly."), their entry into the classroom is depicted with the verb ending lyeko-. This ending, which Sohn (1999: 317) characterizes as the "intentive", further underscores the deliberateness of their actions. While the teacher uses verbal forms which emphasize Jinsok and Byungsok's thoughtfulness and intentions, the other students' behavior is not depicted with these kinds of forms.

The evidential patterning in this narrative thus reveals how grammar helps to construct children as moral types. By using prospective forms of the verb, explicitly deductive frames, and evidential uncertainty markers to describe the actions of the good students, the teacher marks a clear distinction between her subjectivity and those of the students. This use of the culturally preferred "subjective" framework constructs the "good" kids as social beings whose thoughts and sensations are relatively inaccessible to the teacher. Since expressions of uncertainty and distancing are conventionally associated with politeness, the teacher is thereby grammatically constructing the "good" students as more deserving of respect.

When talking about the "bad" students, the teacher uses a different framework in which her presence as an observer of these students is more effaced. By using plain forms of the verb, minimal framing, and no evidential marking to describe the actions of the bad students, the teacher creates a deictic field in which these students' actions, thoughts, and emotions are located as originating directly from their own bodies. This more "objective" framework constructs the "bad" students' minds as more readily readable and does not draw a clear boundary between the teacher's subjectivity and that of the students.

\section{Reading faces}

In the next section, I show how the teacher uses a more objectifying framework as she intensifies her negative assessment. This excerpt takes place less than a minute after the preceding one. The teacher tries to resume class and she asks students to read question number 7. No one responds to her request, and this leads to an extended narrative in which students are chastised for their inattention:

(5) 'It's written all over their faces'

1 Teacher: $\quad$ Sensayng-nim-i cikum mwe ilku-la-ko hay-ss-e Teacher-HT-NOM now what read-IMP-QT do-PST-Q/INT? What did the teacher tell you to read just now?

2 Students: $\quad$ chil-pen seven-number

(Question) number 7

3 Teacher: colli-wun salam 
be sleepy-PRS/RL people

(Is there) anyone who is sleepy?

kuman han-sikan-ccum ca-l-kka?

Stop one hour-about sleep-FUT/RL-Q/PRSM?

Why don't we stop and just sleep for an hour?

Kongpwuha-ci mal- ko?

study-not do-NOML not-CONN

Instead of studying?

6

Etten chinkwu-nun co-n-ta,

Some friend-TOP sleep-IN/DC/PLN

Some friends are dozing off

kuliko etten chinkwu-nun (.2) a onul kkuthna-ko And some friend-TOP ah today finish-CONN mwe-ha-l-kka?

what-do-FUT/RL-Q/ PRSM

And some friends (.2) (are like),

"Hmm, today what should I do after class?"

8

Yakwucang-ka-l-kka?

Baseball field-go- FUT/RL -Q/PRSM?

Syophing-ka-l-kka?

shopping-go- FUT/RL -PRSM?

"Should I go to the baseball game? Should I go shopping?"

9

ani-ya ecekkey nay-ka emma-hanthey kecismal-hay-ssnuntey,

no-be-INT yesterday I-NOM mom-DAT lie-say-PST-CIRCUM "No, I lied to my mom yesterday."

A pay-ka kophu-ntey, (.2) pipi-malyewu-ntey, Ah stomach-NOM hungry-CIRCUM pee-feel an urge-CIRCUM "Oh, I'm hungry. (.2) I want to pee."

((Students laugh)) 
Some-RL friend-TOP

They keep thinking like this, some friends.

((standing up straight))

12

elkwul-ey ta sse-iss-e.

Face-LOC all write-be-INT

It's written all over (their) faces

Kuliko etten chinkwu-nun

And some friend-TOP

ah onul kongpwuha-ki-ka nemwu silh-untey,

ah today study-NOML-NOM too dislike-CIRCUM

And some friends (are like)

"Oh today I really don't want to study"

Nol-ko-man siph-untey,

Play -GRND-only want-CIRCUM.

"I only want to play"

Kulehkey sse-iss-nun chinkwu-to iss-ko.

Like that write-be-RL friend-also be-CONN

There are also friends who have that written (all over their faces).

In contrast with the earlier claims that Korean speakers cannot have access to others' subjectively experienced emotions, sensations, or consciousness, in this narrative the teacher presents herself as able to read these negatively assessed students' private thoughts, emotions, and bodily sensations at length. Through a series of direct quotations, she presents physical sensations which by definition can only be felt by the subject they originate from (e.g. line 10 "Oh, I'm hungry. I want to pee."). She discursively situates herself as having extended access to their private musings (e.g. line 7-8 "Hmm, today, what should I do after class? Should I go to the baseball game? Should I go shopping?"). These thoughts and sensations, which are presented in the form of direct quotations, present students as morally wanting figures to themselves, who lie and are bored and disengaged from the task at hand.

While the direct quotation frame does not violate the grammatical constraints against "subjective" depictions of other persons' thoughts and feelings presented earlier, this narrative certainly seems to demonstrate that some people's thoughts and feelings can be portrayed as directly accessible. Moreover, the framework the teacher uses to discuss these negatively assessed students does not contain the kinds of epistemically uncertain stance markers which were used in the depiction of the positively assessed 
students in excerpt (4). Whereas the quotes attributed to the positively assessed Jinsok and Byungsok earlier were framed with a full sentence and evidentials which highlighted the fact that they were conjectured ("Probably, certainly, they must have been like this"[line 13]) here only the repetition of the subject "etten chinkwunun" ('some friends') introduces the quotations in lines 7 and 13. When speaking about positively assessed students, the teacher thus discursively frames her voice as distinct from theirs. Here, in contrast, there is a maximal melding of voice as the teacher situates herself as a kind of panopticon, with the ability to enter directly into students' minds. This extensive reading of the students' private thoughts reveals how stances of certainty are linked to moral evaluations of others as deficient. Moreover, by foregrounding her unfettered access to these supposedly private thoughts and sensations, presenting her reading of them as highly obvious and sure, and effacing her own interpretive role/voice, the teacher maximizes her authority over the students' subjectivities.

\section{Socializing affect: Nwunchi as a theory of interaction}

This narrative can also be understood as a means through which Korean American children are socialized to a particular theory of affective display. It specifically targets the fact that their boredom is so apparent, literally "written" on their faces. In lines 1112, for example, "They keep thinking like this, some friends. It's written all over (their) faces." and in line 15 "There are friends who have that written (all over their faces)", the teacher highlights how the students' thoughts are available for all to see.

Research on Korean interaction argues that emotional expressiveness is, in fact, not appropriate for occasions in which respect and formality are important. As Cha (1994: 165) notes, "courtesy" in Korean culture is expressed by "suppressing emotions and keeping thoughts to self; not being frank; restrained affective display." The students here are violating that norm, by openly displaying their boredom and wandering thoughts. Here, Korean American students are being instructed in a theory of interaction appropriate for a heritage language classroom where affective restraint and suppression of private thoughts are seen as tokens of respect.

This particular kind of interaction is usually described using the principle of nwunchi. Yum and Canary (2003: 283) define nwunchi as "a uniquely Korean strategy to ascertain the partner's attitudes, desires, and moods [Lim and Choi 1996]. It is a tacit, high-context communication tactic that allows a person to understand indirect or unspoken messages." Nwunchi can be understood as one aspect of a theory of communication which operates in certain Korean contexts, in which interlocutors are supposed to be "catching minute nonverbal cues,... reading between the lines, and ...hearing between the sounds" (Yum 1987: 80) because speakers are understood to be suppressing their "true" thoughts and feelings. ${ }^{7}$ While the students should be

${ }^{7}$ It should be noted that this portrait of emotional restraint and civility does not hold true across Korean contexts, speakers, or settings. See, for example, Hoffman's (1999: 11) description of her first impressions of Korea: "A spirit of drama seemed to pervade everyone and everything. There was little emotional middle ground: euphoria and desperation, exultation and depression-the extremes were everywhere present, sometimes even at the same time and in the same person." and Abelmann's (2003) discussion of the melodramatic sensibility of women in contemporary South Korea. The interplay between emotional display/restraint intersects ideologies of hierarchy and formality, such that displays of strong emotions are linked to intimate relationships and settings, while emotional restraint is associated with formal situations, especially on the part of the subordinate in a hierarchical relationship. 
maintaining an outward demeanor which is not emotionally transparent, thereby requiring others to attempt to read between the lines, their visible boredom violates that norm.

\section{Participation frameworks as dynamic resources}

In the preceding two excerpts, the teacher presents extended "readings" of students' thoughts, feelings, and sensations. Her depictions of students are not explicitly challenged by them; students do not say things like "No, that's not what I am thinking now," or "No, that's not what I meant when I walked into the classroom this morning." The frameworks that the teacher uses for these assessments, I argue, makes these characterizations of students relatively more difficult for children to contest. The indefiniteness of the referent of "some friends" in both excerpts (4) and (5) makes any single child's contestation of the negative assessment potentially troublesome, while the very embeddness of both the positive and negative assessments also does not afford students with a readily accessible interactional space from which to challenge these portrayals.

In fact, these kinds of narratives, in which the teacher purports to project exactly what children are/were thinking, feeling, and intending, tend to follow instances where the teacher uses participation frameworks where students are provided with an opportunity to either ratify or contest a particular moral ideology, and they explicitly defy the teacher. The following excerpt illustrates an earlier attempt in this class by the teacher to socialize promptness:

(6) 'If I came 15 minutes late'

1 Teacher: Taum-cwu-ey sensayng-nim-i, (.2) sipo-pwun cengto yeki nuc-key next week-at teacher-HT-NOM fifteen-minutes about here late-ADV tuleo-myen ette-l-kka.

enter-if how-FUT/RL-Q/PRS

If I came here about 15 minutes late next week, how would that be?

2 Student: $\quad(\quad)$

3 Teacher: e

\section{Mmm}

4 Student: $\quad$ Fifty [pushups

5 Teacher: $\quad[\mathrm{e}$

Mmm

6 Student: $\quad$ Fifty pushups

7 Teacher: e 


\section{Mmm}

8 Student: [Yeah!

9 Student: $\quad[$ Pushups ( )

10 Teacher: E. sensayng-nim-i kulemyen((clears throat)) nine forty five hmm. teacher-HT-NOM then nine forty five ahop-si sasip-o-pwun-ey yeki- o-l-kka-yo nine-hour forty-five-minutes-LOC here come-FUT/RL -Q/PRS-POL Hmm. Shall I come here late, at 9:45, 9:45?

11 Student: Ney

Yes

12 Student: $\quad[$ Ney

Yes

13 Teacher: [Cengmal?

\section{Really?}

In this excerpt, the teacher uses a transposed participation framework (Hanks 1990) to impress upon students the importance of coming to class on time. She asks them how they would feel if she came to class 15 minutes late next week. When several boys in the class chime in with various cries to do pushups, the teacher's utterance in line 10 constructs these as non-aligning responses. ${ }^{8}$ In line 10, she repeats her question "Hmm. Shall I come here late, at 9:45, 9:45?". The fact that the teacher here codeswitches into English, which is relatively rare for her, accentuates her efforts to make the lexical content of her utterance absolutely clear to the students. When other students respond "Ney" or "yes" in Korean, these are interpreted by the teacher as more inappropriate responses, as can be seen by the fact that she initiates repair in line 13 with the question "Really?". Through these repeated questions, the students are constructed as intransigent in their collective refusal to provide the "correct" answer to the teacher's question. When using a participation framework in which students are given an opportunity to demonstrate their (non) alignment with the teacher, the students and the teacher do not come to common agreement on the desirability and importance of being on time.

\section{Conclusion}

In this article, I hope to have demonstrated how an interactional approach to the study of evidential marking can help to reconcile the apparently contradictory claims of previous research on the question of whether Korean speakers can read other people's minds. Whereas descriptions of nwunchi have accentuated how a Korean speaker "tries to read one's mind, probe one's motives, studies one's face; grasps a situation, sees how

\footnotetext{
${ }^{8}$ It is likely that the teacher did not understand the English term "pushups".
} 
the wind blows" (Martin, Lee and Chang 1967: 364) in the course of an interaction, research in functional linguistics has claimed that Korean speakers must mark their access to others' thoughts and sensations as distant and uncertain.

An interactional approach to evidential marking reveals that frameworks of subjectivity are not reflections of speakers' cognitive perspectives on another, but are instead a resource through which speakers evaluate others as kinds of moral beings. When speaking about students she assesses positively, the teacher uses adverbs, presumptive verb constructions, modal verbs and explicit framing of quotes in conjunction with each other to create a stance of epistemic uncertainty. This stance of uncertainty deictically projects the teacher's presence as an observer in a "subjective" participation framework. When speaking about students she assesses negatively, the teacher uses plain forms of the verb and what Hanks (1990) calls "transposed" frames, where she speaks in the voice of the students, minimizing the separation between her own voice and that of the students. This stance of relative epistemic certainty deictically centers descriptions of negatively evaluated students' thoughts, sensations, and feelings within their own bodies, creating instead more "objective" participation frameworks. These epistemically certain stances help to constitute the teacher as a socially powerful kind of person who has access to others' minds while positioning the "bad" students as people who are not deserving of respect. The cultural norm that speakers will use "subjective" frameworks to talk about others' feelings, thoughts, and sensations is therefore not so much a rigid grammatical rule as it is a cultural expectation whose violation is itself a form of moral judgment and self- and other- positioning. Moreover, even in languages where evidentiality is not a highly grammaticalized class, in interaction, speakers nonetheless use widely disparate grammatical forms together to form epistemically coherent kinds of frames.

The expectation that speakers' are in fact always trying to divine their interlocutors' "true" intentions, thoughts, and feelings is another kind of social norm, which is linked to a particular genre of interaction where speakers are understood to be suppressing their genuine emotions and opinions as a form of respect. When the teacher assesses the entire class negatively, her narrative employs an objectifying framework which specifically targets the students' readily apparent display of boredom. This narrative thereby socializes these Korean American students into the importance of maintaining a demeanor which does not reveal such wayward thoughts and is appropriate for a heritage language classroom. These kinds of embedded and extended characterizations of students' thoughts and emotions were not often challenged by them, although other kinds of participation frameworks did provide students with opportunities to be openly defiant of teachers' attempts at promulgating moral ideologies.

This article adds to the growing body of work which looks at evidentiality as a creative resource through which participants create interactionally relevant identities in the moment (e.g. Fox 2001, Raymond and Heritage 2004). Scholars of Korean interaction often focus on the socially valued ways in which speakers index politeness, respect, and social distance through expressions of epistemic uncertainty such as hedges, modal verbs, and negative questions (e.g. Dredge 1983; Park 1990; Sohn 1986a, 1986b). The literature in this area tends to look at such discursive resources as reflections of already existing social distances between people fixed through such attributes as age, professional rank, and generation. What I hope to have demonstrated in this article was that even in cases where age, generation, and social roles are highly 
asymmetric, speakers are nonetheless constantly evaluating and positioning each other as moral subjects through the dynamic means of language.

\section{References}

Abelmann, Nancy (2003) The melodrama of mobility : Women, talk, and class in contemporary South Korea. Honolulu: University of Hawai'i Press.

Agha, Asif (2004) Epistemic stance. Ms.

Aikhenvald, Alexandra Y. (2003) Evidentiality in Tariana. In Alexandra Y. Aikhenvald and Robert M. W. Dixon (eds.), Studies in evidentiality. Amsterdam/Philadelphia: John Benjamins, pp. 131-164.

Benveniste, Emile (1971) Problems in general linguistics. Coral Gables, FL: University of Miami Press. Translated by Mary Elizabeth Meek.

Cha, Jae-Ho (1994) Aspects of individualism and collectivism in Korea. In Uichol Kim, Harry C. Triandis, Çigdem. Kagitçibasi, Sang Chin Choi and Gene Yoon (eds.), Individualism and collectivism: theory, method, and applications. Thousand Oaks, CA: Sage Publications, pp. 157-174.

Choi, Soonja (1991) Early acquisition of epistemic meanings in Korean: A study of sentence-ending suffixes in the spontaneous speech of three children. First Language 11: 93-119.

de Reuse, Wilhem J. (2003) Evidentiality in Western Apache (Athabaskan). In Alexandra Y. Aikhenvald and Robert M. W. Dixon (eds.), Studies in evidentiality. Amsterdam/Philadelphia: John Benjamins, pp. 79-100.

Dredge, C. Paul (1983) What is politeness in Korean speech? Korean Linguistics 3: 21-32.

Fox, Barbara A. (2001) Evidentiality: Authority, responsibility, and entitlement in English conversation. Journal of Linguistic Anthropology 11.2: 167-192.

Garfinkel, Harold (1967) Studies in ethnomethodology. Englewood Cliffs, N.J.: Prentice-Hall.

Hanks, William F. (1990) Referential practice : Language and lived space among the Maya. Chicago: University of Chicago Press.

Hoffman, Diane M. (1999) Lanterns on the river: Essays on life and culture in contemporary South Korea. Lanham, MD: Lexington Books.

Iwasaki, Shoichi (1993) Subjectivity in grammar and discourse: Theoretical considerations and a case study of Japanese spoken discourse. Amsterdam/Philadelphia: John Benjamins.

Kamio, Akio (1995) Territory of information in English and Japanese and psychological utterances. Journal of Pragmatics 24.3: 235-264.

Kamio, Akio (1997) Territory of information. Amsterdam/Philadelphia: John Benjamins.

Kim, Ki-Hong (1978) Cultural and linguistic variables in the language of emotion of Americans and Koreans. In Chin-u Kim, Samuel Elmo Martin, Ho-min Sohn and Seok C. Song (eds.), Papers in Korean linguistics. Columbia, S.C.: Hornbeam Press, pp. 259-267. 
Kuroda, S.-Y. (1973) Where epistemology, style and grammar meet: A case study from the Japanese. In Paul Kiparsky and Stephen R. Anderson (eds.), A festschrift for Morris Halle. New York: Holt Rinehart and Winston, pp. 377-391.

Langacker, Ronald W. (1985) Observations and speculations on subjectivity. In John Haiman (ed.), Iconicity in syntax Amsterdam/Philadelphia: John Benjamins, pp. 109-150.

Lee, Hyo Sang (1993) Cognitive constraints on expressing newly perceived information, with reference to epistemic modal suffixes in Korean. Cognitive Linguistics 4.2: 135-167.

Lyons, John (1982) Deixis and subjectivity: Loquor, ergo sum? In Robert J. Jarvella and Wolfgang Klein (eds.), Speech, place, and action: Studies in deixis and related topics. New York: John Wiley, pp. 101124.

Martin, Samuel Elmo, Yang Ha Lee, and Sung-Un Chang (1967) A Korean-English dictionary. New Haven. Yale University Press.

Maynard, Senko K. (1993) Discourse modality: Subjectivity, emotion and voice in the Japanese language. Amsterdam/Philadelphia: John Benjamins.

McLendon, Sally (2003) Evidentials in eastern Pomo with a comparative survey of the category in other Pomoan languages. In Alexandra Y. Aikhenvald and Robert M. W. Dixon (eds.), Studies in evidentiality. Amsterdam/Philadelphia: John Benjamins, pp. 101-129.

Mushin, Ilana (2001) Evidentiality and epistemological stance: Narrative retelling. Amsterdam/Philadelphia: John Benjamins.

Park, Mae-Ran (1990) Conflict avoidance in social interaction: A sociolinguistic comparison of the Korean and Japanese honorific systems. In Hajime Hoji (ed.), Japanese/Korean linguistics. Stanford, California: Center for the Study of Language and Information, pp. 111-128.

Raymond, Geoffrey, and John Heritage (2004) The epistemics of social relations: Owning grandchildren. Manuscript.

Scheibman, Joanne (2002) Point of view and grammar: Structural patterns of subjectivity in American English conversation. Amsterdam/Philadelphia: John Benjamins.

Silverstein, Michael (1976) Shifters, linguistic categories, and cultural description. In Keith Basso and Henry A. Selby (eds.), Meaning in anthropology. Albuquerque, NM: University of New Mexico Press, pp. 11-56.

Sohn, Ho-Min (1986a) Strategies of indirection in Korean. In Linguistic expeditions. Seoul: Hanshin Publishing Company, pp. 266-279

Sohn, Ho-Min (1986b) Power and solidarity in the Korean language. In Linguistic expeditions. Seoul: Hanshin Publishing Company, pp. 389-410.

Sohn, Ho-Min (1999) The Korean language. Cambridge: Cambridge University Press.

Sohn, Sung-Ock S., and Mee-Jeong Park (2003) Indirect quotations in Korean conversations. In Patricia Clancy (ed.), Japanese/Korean linguistics. Chicago: University of Chicago Press, pp. 105-118.

Suh, Cheong-Soo (1996) Kwuke mwunpep (Korean grammar). Seoul: Hanyang University Press.

Suzuki, Satoko (1998) Tte and nante: Markers of psychological distance in Japanese conversation. Journal of Pragmatics 29.4: 429-462. 


\section{Adrienne Lo}

Yum, June O. (1987) Korean philosophy and communication. In D. Lawrence Kincaid (eds.), Communication theory: Eastern and western perspectives. San Diego, CA: Academic Press, pp. 71-86.

Yum, Young-Ok, and Daniel J. Canary (2003) Maintaining relationships in Korea and the United States: Features of Korean culture that affect relational maintenance beliefs and behaviors. In Daniel J. Canary and Marianne Dainton (eds.), Maintaining relationships through communication: Relational, contextual, and cultural variations. Mahwah, NJ: Lawrence Erlbaum Associates, pp. 277-296. 